\title{
Fatores associados à ocorrência de acidentes de trânsito entre universitários
}

\author{
Factors associated with traffic accidents among university students
}

\author{
Marcos Mesquita Filhoa, Carolina Rodrigues de Carvalho ${ }^{b}$, Elisa de Paula Garcia ${ }^{b}$ \\ a Médico. Doutor em Saúde Pública pela Universidade de São Paulo. Professor Titular na Universidade do Vale do Sapucaí (UNIVÁS).

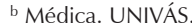

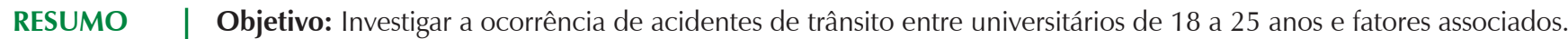
Materiais e Métodos: O estudo transversal, com 500 estudantes. Aplicou-se 3 instrumentos: sociodemográfico, AUDIT (The Alcohol Use Disorder Identification Test), para dependência ao álcool, e YRBS (Youth Risk Behavior Survey), que verificou riscos de acidente de trânsito.

Resultados: Maioria de indivíduos eram mulheres e a idade média foi 21,2 2,1 anos. Uso de álcool em $67,4 \%$ $(n=337)$; sendo 43,2\% $(n=216)$ bebedores de risco e 4,4\% $(n=22)$ usuários de drogas. Dos $71,2 \%(n=356)$ que dirigiam, 63,2\% ( $n=316)$ eram habilitados. Circulava-se principalmente em automóvel e apenas 50,4\% $(n=252)$ dos motoristas e $45,2 \%(n=226)$ passageiros usavam cinto de segurança. Foram $42,0 \%(n=210)$ os que sofreram acidentes, $10,2 \%(n=51)$ no último ano. Houve predomínio masculino $(p \leq 0,05)$ entre os que dirigiam, que sofreram acidentes, que usavam drogas, que dirigiam após uso de álcool no último mês, que praticaram rachas e os que sofreram acidentes como motoristas. As mulheres eram menos respeitadoras do sinal fechado. Sofrer acidente no último ano se associou ao sexo masculino, ao consumo de risco/dependência para o álcool e a trafegar num veículo cujo motorista consumira bebidas alcoólicas.

Conclusão: Quase metade dos universitários haviam sofrido algum acidente, sendo associados ao fato de ser homem, o abuso do álcool e trafegar com um condutor sob efeito de bebidas. Devem ser desencadeadas ações para equacionamento deste importante problema do setor saúde.

Palavras-chave: acidentes de trânsito; adulto jovem; fatores de risco; causas externas; ferimentos e lesões.

\section{ABSTRACT}

Objective: To investigate traffic accidents and its associated factors among university students aged between 18-25 years old.

Materials and Methods: Cross-sectional study with 500 students. Three instruments were applied: sociodemographic, The Alcohol Use Disorder Identification Test (AUDIT), and Youth Risk Behavior Survey (YRBS), to verify traffic accident risks.

Results: The majority of individuals were female and the mean age was 21.2 2.1 years old. Alcohol was used for $67.4 \%(n=337)$; risk drinkers were $43.2 \%(n=216)$ and $4.4 \%(n=22)$ used drugs. Of those $71.2 \%(n=356)$ who drove vehicles, $63.2 \%(n=316)$ had drivers' license. Seat belt was used for $50.4 \%(n=252)$ of the drivers and for $45.2 \%(n=226)$ of the passengers. Forty two percent $(n=210)$ had suffered an accident and $10.2 \%(n=51)$ was in the last year. Men predominated $(p \leq 0.05)$ among those who drive, were injured, used drugs, drove a vehicle after alcohol consumption in the last month, participated in illegal street racing, and who suffered accidents as drivers. Women were less respectful of the traffic lights. Suffering an accident in the past year was associated with male gender, risk consumption / addiction to alcohol and riding in the vehicle whose driver had made use of alcoholic beverages. Conclusion: Almost half of the students had suffered an accident. They were associated with being male, alcohol abuse and ride in a car with a driver under alcohol effect. Actions aimed at addressing this important problem in the health sector should be initiated.

Keywords: traffic accidents; young adult; risk factors; external causes; wounds and injury. 


\section{INTRODUÇÃO}

Os acidentes de trânsito são causadores de alto impacto na saúde da população mundial. Mais de 1,2 milhão de pessoas morrem por ano no mundo em razão desta causa e cerca de 50 milhões sofrem lesões, sendo que de 15,0 a 20,0\% dessas lesões apresentam sequelas ${ }^{1}$. Em países das Américas, as maiores taxas de mortalidade por acidentes com veículos a motor foram encontradas no Brasil2 ${ }^{2}$, que é considerado um dos locais de trânsito mais perigosos do mundo. A mortalidade por acidentes de trânsito no país teve, em média, mais de 30 mil óbitos por ano de 2001 a $2005^{3}$. Seus custos sociais são enormes, correspondendo a valores entre 1,0 a 2,0\% do produto interno bruto dos países de média e baixa renda². Em todo o mundo são os principais responsáveis pela morte de jovens entre 15 e 29 anos $^{4}$, ocupando, no Brasil, o segundo lugar nestas idades 3 .

Entre as variáveis associadas à ocorrência de lesões e mortes no trânsito podem ser destacadas: fatores estruturais (conservação das estradas e das vias urbanas); frota de veículos crescente; o consumo de bebidas alcoólicas associadas à direção; o não uso de equipamentos de segurança, como cintos de segurança dianteiros e traseiros, capacetes, dispositivo de retenção para crianças, airbags, e outros equipamentos 5 . O consumo de álcool é também importante determinante da alta incidência dos acidentes com vítimas. Estima-se que o etilismo esteja associado a $70,0 \%$ dos acidentes com morte ${ }^{6}$. A maioria das vítimas fatais relacionadas ao trânsito (90,0\%) e 91,8\% dos 38 milhões de anos de vida perdidos ajustados por incapacidade ocorrem em países em desenvolvimento. O álcool está presente no sangue de 33,0 a $69,0 \%$ dos condutores envolvidos em acidentes fatais ${ }^{1}$.

As internações por acidentes de trânsito no Brasil corresponderam a uma taxa de 7,7 por dez mil habitantes em 2010. Embora os acidentes de transporte no Brasil afetem indivíduos de todas as idades, o número de internações de jovens é superior ao das outras faixas etárias ${ }^{7}$. A alta morbimortalidade em vítimas jovens vem sendo relacionada à inexperiência na condução de veículos ${ }^{8}$. Características próprias da juventude, como a impulsividade e a necessidade de autoafirmação, além de comportamentos agressivos típicos de adolescentes e jovens como alta velocidade, falta de segurança e principalmente com a ingestão de álcool e drogas também se associam a estes eventos ${ }^{9}$. Geralmente os indivíduos nesta faixa etária, consomem bebidas alcoólicas e drogas com maior frequência do que os adultos, bem como tendem a exceder mais os limites de velocidade e a desobedecer as leis de segurança no trânsito ${ }^{8}$. Outro fato que condiz com a maior incidência no grupo etário jovem é que nos três primeiros anos que o motorista adquire sua Carteira de Habilitação, a frequência destes eventos é uma vez e meia mais alta9.

Os universitários constituem um importante subgrupo da população jovem. Em 2001, de acordo com estudo de Hingson et al. ${ }^{10}$, entre jovens de nível superior norteamericanos, foram relatadas 3003 mortes devido a acidentes de trânsito (38,0\% relacionadas ao consumo de bebidas alcoólicas). Na cidade de Londrina, entre acadêmicos de medicina houve o relato de envolvimento com acidente de trânsito de $65,6 \%$ de estudantes masculinos e de $57,7 \%$ femininos ${ }^{8}$. Num estudo no município de Ponta Grossa ${ }^{11}$ foram encontrados resultados semelhantes, com 66,4 e $53,7 \%$, respectivamente, envolvidos.

O objetivo deste trabalho foi investigar a ocorrência de acidentes de trânsito entre universitários de 18 a 25 anos e fatores associados à sua ocorrência, em Pouso Alegre, Minas Gerais.

\section{MATERIAIS E MÉTODOS}

Trata-se de um estudo analítico, transversal, individual, observacional, não controlado desenvolvido em Pouso Alegre, MG, nas instituições de ensino superior existentes. A população pesquisada foi a de universitários, de ambos os gêneros e de faixa etária entre 18 e 25 anos de idade. Entrevistou-se 500 jovens selecionados por amostragem probabilística, estratificada por instituição de ensino superior.

Foram auto preenchidos um protocolo sociodemográfico e dois outros instrumentos: o AUDIT (The Alcohol Use Disorder Identification Test), desenvolvido sob o patrocínio da OMS (Organização Mundial de Saúde) por Saunders et al. ${ }^{12}$, validado e adaptado para o português do Brasil por Méndez ${ }^{13}$, que é útil para identificar a ingestão prejudicial, potencialmente perigosa de bebidas alcoólicas e provável dependência. Compõe-se de dez questões fechadas cujas respostas são escalas com cinco opções, pontuadas por valores que variam de 0 a 4, com exceção da questão 2, de seis opções com pontuação de 0 a 5 . O escore total é calculado pela soma dos pontos obtidos em cada resposta podendo variar de zero a 41. De acordo com a pontuação obtida definem-se os grupos: De 1 a 7 pontos: consumo de baixo risco; de 8 a 15 pontos: uso de risco; de 16 a 19 pontos: uso nocivo; 20 pontos ou mais: provável dependência.

O terceiro questionário, com questões sobre Acidentes de Trânsito, baseou-se no Youth Risk Behavior Survey (YRBS) do Centers for Disease Control and Prevention $(C D C)$, desenvolvida por Eaton et al. ${ }^{14}$, é utilizado para levantamentos nacionais de comportamentos de risco em jovens dos Estados Unidos da América. O instrumento foi ampliado a partir de variáveis citadas na literatura brasileira 
por Andrade et al. ${ }^{8}$ e Labiak et al. ${ }^{11}$. Como não tem o formato de uma escala, não são obtidos escores com sua aplicação. O instrumento é composto por perguntas de múltipla escolha, onde o entrevistado seleciona a opção pertinente às situações por ele vividas. Foi idealizado, quando usado em sua totalidade, para o levantamento de diversas situações de risco. Entretanto, neste trabalho foram selecionadas somente as questões que eram voltadas para os riscos de acidentes de trânsito. Assim, foram aproveitadas aquelas que versavam sobre consumo de álcool, uso de cinto de segurança, capacete, idade em que aprendeu a dirigir, uso do veículo para diversão, participação em corridas ilegais nas ruas da cidade ("rachas"), envolvimento em acidentes, respeito às regras do trânsito, comportamentos perigosos. $\mathrm{O}$ instrumento foi avaliado por cinco especialistas que julgaram a sua adequação aos objetivos do estudo. Em seguida, foi revisto por um grupo focal composto por seis indivíduos da população de interesse. Por último foi submetido a um estudo piloto com vinte universitários, cujos resultados não foram incluídos na pesquisa final. Todas as inadequações detectadas resultaram em modificações nos itens e submissão destas a nova avaliação.

Os estudantes foram procurados e entrevistados em suas escolas e salas de aula. $\mathrm{O}$ acesso à escola foi autorizado pelo responsável pelo estabelecimento e à classe pelo professor. A pesquisa aconteceu através da aplicação dos questionários auto preenchidos na ocasião. No início dos trabalhos os pesquisadores se apresentavam e explicavam os objetivos e procedimentos da pesquisa, liam e davam informações sobre o Termo de Consentimento Livre e Esclarecido, que era assinado se houvesse concordância em participar. Após isto, o entrevistador, em voz alta, fazia a completa leitura dos instrumentos. Se algum dos pesquisados manifestasse dúvidas sobre qualquer pergunta, era feita a sua releitura, até que o entrevistado manifestasse a compreensão. Não se admitiu que fossem realizadas explicações sobre o conteúdo dos itens da entrevista, para a prevenção de vieses resultantes da influência do entrevistador. Finalizando estes procedimentos os instrumentos eram entregues e auto preenchidos pelos universitários.

As variáveis quantitativas foram descritas pelo cálculo de medidas de tendência central (média e mediana) e de dispersão (desvio padrão), as categóricas por proporções. Intervalos de confiança a 95\% foram calculados. Foram realizadas análises bivariadas pelos testes do qui-quadrado e exato de Fisher. As associações que obtiveram significância estatística foram incluídas nos modelos multivariados. Foram ajustados dois modelos explicativos pela regressão de Poisson com variância robusta: o primeiro estudou associações entre a variável dependente sexo e fatores determinantes dos acidentes de trânsito. O outro buscou um modelo explicativo para a ocorrência de acidentes de trânsitos nos últimos doze meses. Considerou-se significante $p \leq 0,05$.

Este trabalho foi aprovado pelo Comitê de Ética em Pesquisa da Universidade do Vale do Sapucaí (protocolo no 1160/2009) e seguiu a Resolução 196/96 do Conselho Nacional de Saúde e não apresentou conflitos de interesse.

\section{RESULTADOS}

A média idade dos participantes foi de 21,2 $\pm 2,1$ anos. Os indivíduos de cor branca e as mulheres constituíram a maioria da amostra. Mais de $60,0 \%$ usavam bebidas alcoólicas; $12,4 \%$ fumavam e $4,4 \%$ informaram consumir drogas ilícitas. O valor médio do escore do AUDIT foi 7,5 $5 \pm 6,7$, com 43,2\% de usuários de bebidas alcoólicas de risco. A pontuação média deste instrumento foi significativamente maior entre os homens que obtiveram um escore de $9,5 \pm 7,5$ pontos contra $6,1 \pm 5,6$ das mulheres $(p<0,001)$. A maioria informou que sabia dirigir veículos automotivos; tinha carteira de motorista e que possuía veículo (Tabela 1).

Tabela 1. Caracterização da amostra.

\begin{tabular}{|c|c|c|}
\hline Variáveis & Categorias & n (\%) \\
\hline Sexo & $\begin{array}{l}\text { Masculino } \\
\text { Feminino }\end{array}$ & $\begin{array}{l}204(40,8) \\
296(59,2)\end{array}$ \\
\hline Faixa etária & $\begin{array}{l}18 \text { a } 20 \text { anos } \\
21 \text { a } 25 \text { anos }\end{array}$ & $\begin{array}{l}183(36,6) \\
317(63,4)\end{array}$ \\
\hline Cor da pele & $\begin{array}{c}\text { Não branca } \\
\text { Branca }\end{array}$ & $\begin{array}{r}74(14,8) \\
426(85,2)\end{array}$ \\
\hline Trabalho & $\begin{array}{l}\text { Sim } \\
\text { Não }\end{array}$ & $\begin{array}{l}217(43,4) \\
283(56,6)\end{array}$ \\
\hline Saber dirigir & $\begin{array}{l}\text { Sim } \\
\text { Não }\end{array}$ & $\begin{array}{l}356(71,2) \\
143(28,6)\end{array}$ \\
\hline Possuir veículo & $\begin{array}{l}\text { Sim } \\
\text { Não }\end{array}$ & $\begin{array}{l}203(40,6) \\
297(59,4)\end{array}$ \\
\hline Carteira Nacional de Habilitação & $\begin{array}{l}\text { Sim } \\
\text { Não }\end{array}$ & $\begin{array}{l}316(63,2) \\
184(36,8)\end{array}$ \\
\hline Tabagismo & $\begin{array}{l}\text { Sim } \\
\text { Não }\end{array}$ & $\begin{array}{r}61(12,2) \\
439(87,8)\end{array}$ \\
\hline Consumo de bebidas alcoólicas & $\begin{array}{l}\text { Sim } \\
\text { Não }\end{array}$ & $\begin{array}{l}337(67,4) \\
163(32,6)\end{array}$ \\
\hline Uso de Drogas & $\begin{array}{l}\text { Sim } \\
\text { Não }\end{array}$ & $\begin{array}{r}22(4,4) \\
478(95,6)\end{array}$ \\
\hline Tratamento de saúde & $\begin{array}{l}\text { Sim } \\
\text { Não }\end{array}$ & $\begin{array}{c}41(8,2) \\
459(91,8)\end{array}$ \\
\hline Uso de medicamentos & $\begin{array}{l}\text { Sim } \\
\text { Não }\end{array}$ & $\begin{array}{r}66(13,2) \\
434(86,8)\end{array}$ \\
\hline Dependência de bebidas alcoólicas & $\begin{array}{c}\text { Risco/Alto risco/ } \\
\text { Dependência } \\
\text { Não bebe/Baixo risco }\end{array}$ & $\begin{array}{l}216(43,2) \\
284(56,8)\end{array}$ \\
\hline Acidente de trânsito & $\begin{array}{l}\text { Sim } \\
\text { Não }\end{array}$ & $\begin{array}{l}210(42,0) \\
290(58,0)\end{array}$ \\
\hline Acidente de trânsito no último ano & $\begin{array}{l}\text { Sim } \\
\text { Não }\end{array}$ & $\begin{array}{r}51(10,2) \\
449(89,8)\end{array}$ \\
\hline
\end{tabular}


O tipo de transporte predominante foi o automóvel. Cerca de um terço dos entrevistados eram os condutores dos veículos e um quinto passageiros. O cinto de segurança era sempre usado por $73,0 \%$ daqueles que se declaravam motoristas. A proporção era bem menor quando eram passageiros. Os universitários relataram em mais da metade das entrevistas terem aprendido a dirigir após a idade de 16 anos (Tabela 2). Foram 39,2\% os que relatavam ingerir bebidas alcoólicas antes de dirigir. No último mês, a maioria chegou a trafegar com um motorista alcoolizado, ou dirigiu após uso de bebidas.

Foi informado que $85,0 \%$ usavam veículos para comparecer a atividades de diversão e que $88,4 \%$ o faziam acompanhados por amigos. Nestas ocasiões, apenas $27,2 \%$ informaram a existência de pessoa que se abstinha de beber para dirigir para o grupo. A maioria dos entrevistados informou que trafegava sempre nos limites de velocidade, respeitava a sinalização, nunca ou raramente ultrapassava outros veículos em locais proibidos, não fazia conversões ilegais e não estacionava sobre faixas de pedestres. Entretanto, 57 universitários relataram a participação em "rachas" e 11,0\% usavam telefones celulares ao dirigir.

O envolvimento em algum acidente de trânsito foi relatado por $42,0 \%$; sendo $10,2 \%$ no último ano, com $1,2 \%$ sofrendo lesões graves. Os acidentes ocorreram respectivamente em automóveis, motocicletas ou pedestres. Somente $10,6 \%$ relataram que nunca tiveram amigos que se acidentaram.

Os homens sofreram mais acidentes do que as mulheres. A Tabela 3 mostra como os fatores associados a acidentes de trânsito se comportaram por sexo num modelo multivariado. Mantiveram-se como fatores de risco para homens saber dirigir; usar drogas; ser classificado pelo AUDIT como consumidor alcoólico de risco, de alto risco ou dependente (8 pontos ou mais); dirigir nos últimos 30 dias após uso desta substância; ser, ao sofrer um acidente, o condutor do veículo; se tornar motorista antes dos 16 anos de idade. Não parar em sinais fechados foi o único dos determinantes em que predominava nas mulheres de maneira significativa $(p=0,04)$.

Ao se estudar a variável dependente "sofrer acidente de trânsito nos últimos doze meses", ajustou-se modelo multivariado. A Tabela 4 mostra as associações de risco que permaneceram estatisticamente significantes para a variável dependente "sofrer acidente de trânsito nos últimos doze meses": ser do sexo masculino, ser consumidor ou dependente de bebidas alcoólicas e transitar nos últimos trinta dias em automóvel conduzido por motorista alcoolizado.
Tabela 2. Vítimas, comportamentos e determinantes dos acidentes de trânsito.

\begin{tabular}{|c|c|c|}
\hline Variáveis & Categorias & n (\%) \\
\hline \multirow[t]{5}{*}{ Meio de transporte usual } & Pedestre & $138(27,6)$ \\
\hline & Transporte Coletivo & $59(11,8)$ \\
\hline & Automóvel & $273(54,6)$ \\
\hline & Motocicleta & $22(4,4)$ \\
\hline & Bicicleta & $8(1,6)$ \\
\hline \multirow{2}{*}{$\begin{array}{l}\text { Uso de cinto de segurança se } \\
\text { passageiro }\end{array}$} & Não ou irregular & $274(54,8)$ \\
\hline & Sempre & $226(45,2)$ \\
\hline \multirow[t]{2}{*}{ Uso de cinto de segurança se motorista } & Não ou irregular & $135(27,0)$ \\
\hline & Sempre & $252(50,4)$ \\
\hline \multirow{2}{*}{$\begin{array}{l}\text { Circular em veículo dirigido por } \\
\text { motorista alcoolizado }\end{array}$} & Sim & $331(66,2)$ \\
\hline & Não & $169(33,8)$ \\
\hline \multirow{2}{*}{$\begin{array}{l}\text { Ingerir bebidas alcoólicas antes de } \\
\text { dirigir }\end{array}$} & Sim & $196(39,2)$ \\
\hline & Não & $304(60,8)$ \\
\hline \multirow[t]{2}{*}{ Dirigir alcoolizado nos últimos 30 dias } & Sim & $305(61,0)$ \\
\hline & Não & $195(39,0)$ \\
\hline \multirow[t]{2}{*}{ Faixa etária com que aprendeu a dirigir } & Menos de 16 & $117(23,4)$ \\
\hline & 16 anos ou mais & $269(53,8)$ \\
\hline \multirow{2}{*}{$\begin{array}{l}\text { Usa veículo para comparecer a } \\
\text { atividades de diversão }\end{array}$} & Sim & $425(85,0)$ \\
\hline & Não & $75(15,0)$ \\
\hline \multirow[t]{2}{*}{ Participação em "rachas" } & Sim & $57(11,4)$ \\
\hline & Não & $443(88,6)$ \\
\hline \multirow{2}{*}{$\begin{array}{l}\text { Acidente nos últimos } 12 \text { meses após } \\
\text { consumo de álcool }\end{array}$} & Sim & $12(2,4)$ \\
\hline & Não & $488(97,6)$ \\
\hline \multirow{5}{*}{$\begin{array}{l}\text { Tipo de transporte em acidente } \\
\text { de trânsito sofrido em qualquer } \\
\text { circunstância }\end{array}$} & Pedestre & $12(2,4)$ \\
\hline & Automóvel & $79(15,8)$ \\
\hline & Motocicleta & $19(3,8)$ \\
\hline & Bicicleta & $5(1,0)$ \\
\hline & Outro & $4(0,8)$ \\
\hline \multirow{2}{*}{$\begin{array}{l}\text { Lesão grave por acidente nos últimos } \\
12 \text { meses }\end{array}$} & Sim & $6(1,2)$ \\
\hline & Não & $494(98,8)$ \\
\hline \multirow[t]{3}{*}{ Acidente com amigos } & Sim & $321(64,2)$ \\
\hline & Não & $53(10,6)$ \\
\hline & Não sabe & $126(25,2)$ \\
\hline \multirow[t]{2}{*}{ Trafegar nos limites de velocidade } & Sim & $323(64,6)$ \\
\hline & Não/raramente & $36(7,2)$ \\
\hline \multirow[t]{2}{*}{ Respeitar o sinal de trânsito } & Sim & $10(2,0)$ \\
\hline & Não/raramente & $348(69,6)$ \\
\hline \multirow[t]{2}{*}{ Ultrapassar em local proibido } & Sim & $10(2,0)$ \\
\hline & Não/raramente & $348(69,6)$ \\
\hline \multirow[t]{2}{*}{ Conversões em local proibido } & Sim & $7(1,4)$ \\
\hline & Não/raramente & $351(70,2)$ \\
\hline \multirow[t]{2}{*}{ Estacionar sobre a faixa de pedestres } & Sim & $5(1,0)$ \\
\hline & Não/raramente & $353(70,6)$ \\
\hline \multirow[t]{2}{*}{ Uso do celular ao dirigir } & Sim & $55(11,0)$ \\
\hline & Não/raramente & $303(60,6)$ \\
\hline
\end{tabular}


Tabela 3. Fatores de risco para acidentes de trânsito associados à variável sexo.

\begin{tabular}{|c|c|c|c|c|c|c|c|}
\hline \multirow{2}{*}{ Variáveis } & \multirow{2}{*}{ Sexo } & \multirow{2}{*}{$\mathbf{n}$} & \multirow{2}{*}{$\%$} & \multicolumn{2}{|c|}{ Análise bivariada } & \multicolumn{2}{|c|}{ Análise multivariada ${ }^{c}$} \\
\hline & & & & RP & IC95\% & RP & IC95\% \\
\hline \multirow[t]{2}{*}{ Saber dirigir } & Masculino & 165 & 81,3 & $1,26^{*}$ & $1,13-1,40^{\mathrm{a}}$ & $1,50^{*}$ & $1,29-1,76$ \\
\hline & Feminino & 191 & 64,5 & 1 & & 1 & \\
\hline \multirow[t]{2}{*}{ Uso de Drogas } & Masculino & 19 & 9,3 & $9,19^{*}$ & $2,76-30,65^{b}$ & $2,94^{*}$ & $1,11-7,79$ \\
\hline & Feminino & 3 & 1,0 & 1 & & 1 & \\
\hline \multirow{2}{*}{$\begin{array}{l}\text { Dirigir após uso de bebidas alcoólicas nos } \\
\text { últimos } 30 \text { dias }\end{array}$} & Masculino & 154 & 75,5 & $1,48^{*}$ & $1,29-1,70^{\mathrm{a}}$ & $1,32^{*}$ & $1,20-1,45$ \\
\hline & Feminino & 151 & 51,0 & 1 & & 1 & \\
\hline \multirow[t]{2}{*}{ Aprendeu a dirigir com menos de 16 anos } & Masculino & 83 & 40,7 & $3,54^{*}$ & $2,48-5,06^{\mathrm{a}}$ & $1,56^{*}$ & $1,32-1,85$ \\
\hline & Feminino & 34 & 11,5 & 1 & & 1 & \\
\hline \multirow[t]{2}{*}{ Rachas } & Masculino & 38 & 18,6 & $2,90^{*}$ & $1,72-4,89^{a}$ & $1,30^{*}$ & $1,06-1,59$ \\
\hline & Feminino & 19 & 6,4 & 1 & & 1 & \\
\hline \multirow[t]{2}{*}{ Acidente como motorista do veículo } & Masculino & 27 & 13,2 & $4,35^{*}$ & $2,09-9,06$ & $1,42^{*}$ & $1,07-1,87$ \\
\hline & Feminino & 9 & 3,0 & 1 & & 1 & \\
\hline \multirow[t]{2}{*}{ Não parar em sinal fechado } & Masculino & 1 & 0,5 & $0,16^{*}$ & $0,02-1,26^{b}$ & $0,61^{*}$ & $0,46-0,82$ \\
\hline & Feminino & 9 & 3,0 & 1 & & 1 & \\
\hline
\end{tabular}

* Significante estatisticamente: $p \leq 0,05$.

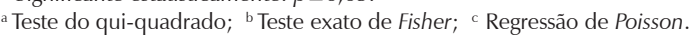

Tabela 4. Variáveis associadas a "Sofrer acidente de Trânsito nos últimos 12 meses".

\begin{tabular}{|c|c|c|c|c|c|c|c|}
\hline \multirow{2}{*}{ Variáveis } & \multirow{2}{*}{ Opções } & \multicolumn{2}{|c|}{ Acidente ano anterior } & \multicolumn{2}{|c|}{ Análise bivariada } & \multicolumn{2}{|c|}{ Análise multivariada ${ }^{c}$} \\
\hline & & $\mathbf{n}$ & $\%$ & RP & IC95\% & RP & IC $95 \%$ \\
\hline \multirow[t]{2}{*}{ Sexo } & Masculino & 35 & 17,2 & $3,17^{*}$ & $1,81-5,58^{a}$ & $1,09 *$ & $1,04-1,13$ \\
\hline & Feminino & 16 & 5,4 & 1 & & 1 & \\
\hline \multirow[t]{2}{*}{ Cor da pele } & Não branca & 13 & 17,6 & $1,97^{*}$ & $1,10-3,52^{\mathrm{a}}$ & 0,94 & $0,84-1,07$ \\
\hline & Branca & 38 & 8,9 & 1 & & 1 & \\
\hline \multirow[t]{2}{*}{ Saber dirigir } & Não & 7 & 4,9 & $0,40^{*}$ & $0,18-0,85^{a}$ & 0,99 & $0,93-1,07$ \\
\hline & Sim & 44 & 12,4 & 1 & & 1 & \\
\hline \multirow[t]{2}{*}{ Possuir veículo } & Não & 22 & 7,4 & $0,52^{*}$ & $0,31-0,88^{a}$ & 0,97 & $0,92-1,02$ \\
\hline & Sim & 29 & 14,3 & 1 & & 1 & \\
\hline \multirow[t]{2}{*}{$\mathrm{CNH}$} & Sim & 41 & 13,0 & $2,39 *$ & $1,23-4,65^{a}$ & 1,05 & $0,98-1,12$ \\
\hline & Não & 10 & 5,4 & 1 & & 1 & \\
\hline \multirow[t]{2}{*}{ Tabagismo } & Sim & 11 & 18,0 & $1,01^{*}$ & $1,07-3,65^{\mathrm{a}}$ & 1,02 & $0,84-1,24$ \\
\hline & Não & 40 & 9,1 & 1 & & 1 & \\
\hline \multirow[t]{2}{*}{ Uso de Drogas } & Sim & 6 & 27,3 & $2,90^{*}$ & $1,39-6,05^{b}$ & 1,09 & $0,96-1,23$ \\
\hline & Não & 45 & 9,4 & 1 & & 1 & \\
\hline \multirow[t]{2}{*}{ Dependência de álcool } & Risco/Alto risco/Dependência & 34 & 15,7 & $2,63^{*}$ & $1,51-4,58^{\mathrm{a}}$ & $1,05^{*}$ & $1,01-1,09$ \\
\hline & Não bebe/Baixo risco & 17 & 6,0 & 1 & & 1 & \\
\hline \multirow[t]{2}{*}{ Ingerir álcool antes de dirigir } & $\operatorname{Sim}$ & 29 & 14,8 & $2,05^{*}$ & $1,21-3,45^{\mathrm{a}}$ & 0,96 & $0,91-1,02$ \\
\hline & Não & 22 & 7,2 & 1 & & 1 & \\
\hline \multirow[t]{2}{*}{ Uso de cinto de segurança se motorista } & Não & 21 & 15,6 & $1,89 *$ & $1,12-3,19^{a}$ & 1,15 & $0,98-1,34$ \\
\hline & $\operatorname{Sim}$ & 30 & 8,2 & 1 & & 1 & \\
\hline \multirow{2}{*}{$\begin{array}{l}\text { Circular em veículo dirigido por } \\
\text { motorista alcoolizado }\end{array}$} & Sim & 42 & 12,7 & $2,38^{*}$ & $1,19-4,78^{\mathrm{a}}$ & $1,06^{*}$ & $1,01-1,10$ \\
\hline & Não & 9 & 5,3 & 1 & & 1 & \\
\hline \multirow[t]{2}{*}{ Participar de "rachas" } & $\operatorname{Sim}$ & 15 & 26,3 & $3,23^{*}$ & $1,90-5,53^{\mathrm{a}}$ & 1,16 & $0,94-1,43$ \\
\hline & Não & 36 & 8,1 & 1 & & 1 & \\
\hline \multirow[t]{2}{*}{ Ultrapassar em locais proibidos } & Sim & 3 & 30,0 & $3,06^{*}$ & $1,15-8,19^{b}$ & 1,13 & $0,82-1,57$ \\
\hline & Não & 48 & 9,8 & 1 & & 1 & \\
\hline
\end{tabular}

* Significante estatisticamente: $p \leq 0,05$.

a Teste do qui-quadrado; ${ }^{\text {b }}$ Teste exato de Fisher; ' Regressão de Poisson. 


\section{DISCUSSÃO}

A população jovem é a mais vulnerável aos acidentes de trânsito ${ }^{15}$. A inexperiência, somada aos estilos de vida próprios da juventude, aumenta a chance de sua ocorrência. Características dos jovens como a impulsividade, a ousadia e a busca por novidades ampliam ainda mais este risco ${ }^{9,11}$.

Esta amostra apresentou características sociodemográficas comuns às de outras populações universitárias brasileiras. Seus resultados foram semelhantes aos encontrados para a região sudeste do Brasil no I Levantamento Nacional Sobre Uso de Tabaco, Álcool e Drogas entre Universitários das 27 Capitais Brasileiras ${ }^{16}$. Estudantes de Londrina ${ }^{8}$, Campinas ${ }^{17}$ e das capitais brasileiras ${ }^{16}$ apresentaram poder aquisitivo relativamente mais elevado. Num estudo na população de Goiânia, entre jovens acidentados, foram encontrados resultados divergentes, com o predomínio de baixo poder aquisitivo e com apenas 19,1\% que eram exclusivamente estudantes ${ }^{18}$.

A maioria dos entrevistados informou ser capaz de dirigir um veículo e ser portadora de Carteira Nacional de Habilitação $(\mathrm{CNH})$. No estudo de Londrina ${ }^{8}$, que abrangeu estudantes de medicina, foi encontrada uma proporção de habilitados maior (86,2\%). A alta porcentagem de alunos que se declarou motorista, assim como a de jovens habilitados, tem também relação com a inserção socioeconômica deste grupo. No Brasil, a maior parte dos universitários é oriunda da classe média ou alta e tem fácil acesso aos automóveis.

Pequena proporção dos entrevistados relataram uso de tabaco, e drogas ilícitas. Entretanto, a maioria declarou-se usuária de bebidas alcoólicas. A entrada na Universidade, por ser um momento de afirmação da autonomia, muitas vezes leva aos jovens à busca destas substâncias ${ }^{16}$. Consumo alcoólico mais exacerbado foi encontrado em estudantes de São Paulo ${ }^{19}$ e também num trabalho em Curitiba $^{20}$. Entretanto, em Porto Alegre ${ }^{21}$, este hábito ocorria em menores proporções. O levantamento nacional sobre o uso de álcool, tabaco e outras drogas, realizado em 2010, também levantou porcentagens mais altas de usuários destas substâncias, tanto nos resultados gerais, como nos das universidades privadas e também nos da região sudeste ${ }^{16}$. Entretanto, os valores encontrados no trabalho atual, podem ser considerados elevados. Além disso, estes resultados podem estar subestimados, uma vez que os dados foram obtidos por auto relato, onde pode ocorrer omissão da verdade, por se tratarem de situações que o respondente não deseja ou teme divulgar seu consumo. Alta proporção dos entrevistados se encontravam em faixas de consumo perigoso, uso prejudicial ou dependência de bebidas alcoólicas. Este resultado assemelhou-se ao de discentes de diversos cursos da área da saúde em Porto Alegre ${ }^{22}$. Pillon et al. ${ }^{23}$, em Ribeirão Preto, ao pesquisarem estudantes de Enfermagem, bem como, Baumgarten et al. ${ }^{21}$, entre universitários de diversas áreas biológicas de Porto Alegre, obtiveram proporções bem inferiores. Num inquérito nacional sobre uso de drogas e álcool por motoristas, realizado nos EUA em 2007, verificou-se uma prevalência de $25,2 \%$ de indivíduos com algum tipo de consumo perigoso ${ }^{24}$. O escore médio do AUDIT encontrado no estudo atual $(7,5)$ é muito próximo ao do valor máximo para consumo de baixo risco.

A maioria dos universitários tinha como meio de transporte preferencial o automóvel, o que se assemelhou a outros estudos realizados com esta população ${ }^{8,11}$. No estudo de Ponta Grossa ${ }^{11}$, importante parcela dos estudantes utilizava transporte coletivo, fato que não ocorreu neste trabalho. Verificou-se nesta pesquisa uma presença considerável de pedestres, porque muitos dos entrevistados, por serem oriundos de outras cidades, residiam nas imediações das suas escolas. Labiak et al. ${ }^{11}$ também apresentou resultado distinto, com uma proporção menor de estudantes que se deslocavam a pé.

Um número expressivo de entrevistados admitiu o uso de bebidas alcoólicas antes de dirigir, resultados semelhantes aos do estudo Andrade et al. ${ }^{8}$. Além disso, foi alta a proporção de estudantes que relatou esse tipo de comportamento nos 30 dias anteriores à pesquisa, mais do que três vezes superior ao constatado em inquérito nacional ${ }^{16}$. Entre universitários, o uso de bebidas alcoólicas, associadas à condução de veículos automotores, é sabidamente um dos principais fatores de risco para a morbimortalidade por acidentes de trânsito, constituindo-se em um dos problemas de saúde mais prevalentes entre eles, assim como, uma das causas significativas da perda de anos potenciais de vida, ajustados por incapacidade ${ }^{16}$. Também chamou a atenção o grande número de jovens que se arriscou ao trafegar, nos últimos 30 dias, em veículo dirigido por motorista alcoolizado (66,2\%), proporção que foi muito superior à do estudo de Londrina ${ }^{8}$ ou à do trabalho que abrangeu todo o Brasil ${ }^{16}$.

Alta proporção dos estudantes comparecia às atividades de diversão (festas, "baladas", raves) em automóveis. Por serem ocasiões propícias ao consumo de bebidas alcoólicas e outras drogas e à perda de horas de sono, o risco de acidentes de trânsito se amplia. A participação em "rachas" foi relatada por $11,4 \%$. Este resultado foi mais alto que o de Campinas ${ }^{17}$ e semelhante ao de Londrina ${ }^{8}$. Trata-se de comportamento de exposição ao risco tanto das pessoas que se encontram no interior, como das que estão fora do veículo. Caracterizamse pelo tráfego em alta velocidade, no tecido viário urbano, transgredindo as normas de trânsito, muitas vezes após uso de substâncias como álcool ou outras drogas. 
O uso do cinto de segurança é importante estratégia para prevenção de morbimortalidade e de incapacidade entre os usuários de veículos de transporte terrestre ${ }^{25}$. Ao se comparar o estudo atual com outros que abrangeram populações universitárias, o cinto de segurança foi pouco utilizado $8,11,14$. Pouco mais da metade dos jovens informou que quando era passageiro de um automóvel sempre colocava o cinto de segurança. Nas situações em que era motorista esta porcentagem foi bem mais elevada. $\mathrm{O}$ uso deste equipamento no banco traseiro apresentou uma proporção muito baixa, fato que é usual no Brasil ${ }^{5,},{ }^{8}$. É preocupante ver que, apesar de sua efetividade já estar consagrada, ser obrigatório por lei, ter uma divulgação massiva de sua importância; uma parcela altamente escolarizada da população jovem não utilizava rotineiramente o cinto de segurança.

Uma concepção presente em parte dos jovens é a de que o bom motorista deve ser agressivo, não se importando em exercer comportamento transgressor e de risco $^{17}$. O descumprimento de regras de trânsito foi relatado por pequena porção dos entrevistados. Outros estudos mostraram uma maior proporção dos que assim se comportavam ${ }^{8,17}$. A desatenção também é um importante determinante dos acidentes. Entre as situações que a provocam está o uso de telefones celulares ao volante. Nos EUA estima-se que 75,0\% dos jovens e adolescentes usam o equipamento ao dirigir, ora para conversar, ora enviando e recebendo mensagens de texto durante os trajetos ${ }^{26}$. Neste estudo foram poucos os que admitiram esta prática. Assim como em relação ao uso/ abuso de substâncias, a admissão de quebra de normas legais causa constrangimento e receio de receber punições. Assim sendo, estes resultados podem estar subestimados

A proporção de universitários que relatou ter sido vítima de algum acidente de trânsito foi alta. A porcentagem, apesar de elevada, ainda foi menor que a encontrada em outros trabalhos ${ }^{8,11}$. Foram $10,2 \%$ os que se acidentaram até um ano antes da data da pesquisa. Poucos admitiram ter ingerido bebidas alcoólicas antes do acidente ou de sofrer lesão grave na ocasião. Os estudantes que dirigem após beber apresentam um risco 184\% maior de sofrerem acidentes, mas é baixa a proporção dos que reconhecem esse fator como de risco ${ }^{17}$. Como em outros estudos $8,11,16,17$ com amostras semelhantes, a maior parte dos acidentes teve a participação de automóveis. Os resultados observados são compatíveis com a existência de muitos acidentes de baixa gravidade, sem lesões ou com agravos leves, que por não trazerem maiores consequências, podem não ter sido considerados e relatados na pesquisa.

Os homens apresentaram maior probabilidade de serem vítimas de acidentes de trânsito que as mulheres. Isso pode refletir o fato de que eles têm maior tendência de estar nas ruas, geralmente por razões socioculturais e maior propensão a assumir riscos ${ }^{15}$. Estes comportamentos se tornam mais agudos entre rapazes menores de 25 anos $^{8,15}$. Neste estudo a razão entre os sexos foi de 3,2 acidentes masculinos nos últimos 30 dias por um feminino. No estudo de Andrade et al. ${ }^{8}$ esta razão foi de 1,3 . Ocorreram diferenças significantes entre as exposições de homens e mulheres a determinantes de acidentes. Na análise bivariada 24 variáveis se associaram aos sexos: 23 ao masculino e apenas uma ao feminino. Entretanto, ao se realizar a análise multivariada, somente sete delas se mantiveram no modelo, reiterando uma maior exposição a fatores de risco pelos homens. As que se associaram ao sexo masculino foram saber dirigir; usar drogas; dirigir nos últimos 30 dias após usar bebidas; se tornar motorista antes dos 16 anos; participar de rachas; ter se acidentado como motorista de um veículo. Estes resultados são confirmados por outros realizados em circunstâncias parecidas ${ }^{8,11,17}$. As mulheres mantiveram, após regressão de Poisson, a maior propensão de avançar sinais de trânsito fechados, 39\% superior à dos homens. Este resultado divergiu do encontrado Andrade et al. ${ }^{8}$ e por Marin-León ${ }^{17}$ onde principalmente os homens desrespeitavam o sinal. A maior prevalência de fatores de risco para os homens indica a necessidade de ações de saúde abordando suas atitudes e comportamentos no trânsito. A promoção à saúde é importante nas questões que envolvem uso de substâncias que exercem efeito no sistema nervoso central e que propiciam comportamentos de violência, além dos riscos associados às esferas cultural e comportamental ${ }^{16}$.

As variáveis sociodemográficas, associadas à ocorrência de acidentes de trânsito no ano anterior, que apresentaram diferenças, estatisticamente significantes, foram ser sexo masculino, reiterando, como já foi constatado, o maior risco dos homens, ter sido apontado pelo AUDIT como de uso problemático de bebidas alcoólicas e finalmente, trafegar nos últimos 30 dias em veículo conduzido por motorista que usou desta substancia. O álcool pode afetar a direção de uma maneira complexa, que tanto reduz a capacidade de dirigir, como aumenta a ocorrência dos comportamentos de risco ${ }^{27}$. Este fato não ocorre somente entre os motoristas, mas também com passageiros, motociclistas, ciclistas ou pedestres. Esse achado demonstra mais uma vez a importância da prevenção do uso desta substância. Mais da metade dos jovens se expuseram a este determinante, reforçando a relevância de ações preventivas sobre o binômio alcoolismotrânsito. Usar um veículo dirigido por alguém que consumiu álcool, além de aumentar a possibilidade de acidentes, tem diminuído a expectativa de vida de universitários no Brasil ${ }^{16}$. Num inquérito dos Estados Unidos da América ${ }^{14}$, após desencadeamento de ações de promoção e prevenção, 
foi observado progresso em relação à diminuição deste comportamento entre estudantes do terceiro grau, com tendência ao decréscimo da sua prevalência entre 1991 e 2009.

Este estudo apresentou algumas limitações que devem ser consideradas na discussão dos resultados. Inicialmente, por se tratar de estudo com parcela diferenciada da população jovem, de poder aquisitivo e escolaridade mais elevadas, a busca de generalizações deve ser feita cuidadosamente, tomando-se a precaução de situá-las no âmbito dos estudantes universitários. Além disto, por ser tema, muitas vezes relacionado com situações em que o sujeito reluta em assumir a sua participação, por serem ilegais, de natureza íntima, ou por acreditar que possa sofrer represálias, podem ter ocorrido omissões ou mesmo inverdades em algumas das respostas coletadas. Este é um problema de âmbito mundial e se relaciona com questionários auto respondidos. Para tentar contorná-lo foram adotados procedimentos para garantir ao respondente a privacidade e a sua não exposição no momento de preenchimento do instrumento.

Pode-se afirmar que pela sua alta morbimortalidade, por trazer consequências graves à saúde dos acidentados, por sobrecarregarem os serviços de saúde, apresentarem altíssimos custos econômicos, sociais e pessoais, os acidentes de trânsito são importante problema de saúde pública. Além disso, estas situações afetam às famílias e às pessoas próximas às vítimas, muitas vezes desestruturandoas pessoal, financeira e emocionalmente. Estudos com estudantes universitários, apesar não cobrirem a totalidade da população jovem do país, são importantes e devem ser incentivados. Trata-se de grupo populacional relevante, que apresenta características peculiares. O conhecimento aprofundado dos fatores e circunstâncias que levam homens e mulheres jovens assumirem comportamentos e atitudes que trazem riscos à sua vida e saúde precisam ser melhor esclarecidos e indicam a necessidade de mais estudos sobre o tema. Os resultados obtidos podem ser importantes para definição de políticas voltadas a esta população e ações a serem desenvolvidas desde a infância e que se prolonguem por todo o transcorrer da vida, e também para o manejo das situações do trânsito, planejamento urbano e do atendimento aos acidentados, e ainda, para importantes questões sociais, culturais e comportamentais.

\section{REFERÊNCIAS}

1. Peden M, Scurfield R, Sleet D, Mohan D, Hyder AA, Jarawan E, Matters C. World Report on Traffic Injury Prevention. Geneva: WHO; 2004

2. Pan American Health Organization. Deaths from motor vehicle traffic accidents in selected countries of the Americas, 1985-2001. Epidemiol Bull. 2004;25(1):2-5.
3. Mello Jorge MHP, Koizumi MS. Acidentes de trânsito no Brasil: um atlas de sua distribuição. São Paulo: ABRAMET; 2007.

4. Mascarenhas MDM, Monteiro RA, Sá NNB, Gonzaga LAA, Neves ACM, Roza DL, Silva MMMA, Duarte EC, Malta DC. Epidemiologia das Causas externas no Brasil: mortalidade por acidentes e violências no período de 2000 a 2009. In: Brasil. Ministério da Saúde. Secretaria de Vigilância em Saúde. Departamento de Análise de Situação em Saúde. Saúde Brasil 2010: uma análise da situação de saúde e de evidências selecionadas de impacto de ações de vigilância em saúde. Brasília: Ministério da Saúde; 2011.

5. Malta DC, Mascarenhas MDM, Bernal RTI, Silva MMA, Pereira CA, Minayo MCS, Morais Neto OL. Análise das ocorrências das lesões no trânsito e fatores relacionados segundo resultados da Pesquisa Nacional por Amostra de Domicílios (PNAD) - Brasil, 2008. Ciênc Saúde Coletiva. 2011;16(9): 3679-87. https://doi.org/10.1590/ S1413-81232011001000005

6. Lima JMB. Alcoologia: o alcoolismo na perspectiva da saúde pública Rio de Janeiro: Med Book Editora Cientifica; 2008.

7. Brasil. Ministério da Saúde. Secretaria de Vigilância em Saúde. Impacto da violência na saúde dos brasileiros. Brasília: Ministério da Saúde; 2005.

8. Andrade SM, Soares DA, Braga GP, Moreira JH, Botelho, JMF. Comportamentos de risco para acidentes de trânsito: um inquérito entre estudantes de medicina na região sul do Brasil. Rev Assoc Med Bras. 2003;49(4):439-44. https://doi.org/10.1590/S010442302003000400038

9. Marín-León L, Queiroz MS. A atualidade dos acidentes de transito na era da velocidade: uma visão geral. Cad Saúde Pública. 2000;16(1): 7-21. https://doi.org/10.1590/S0102-311X2000000100002

10. Hingson R, Heeren T, Winter M, Wechsler H. Magnitude of alcohol-related mortality and morbidity among U.S. college students ages 18-24: changes from 1998 to 2001. Annu Rev Public Health. 2005;26:259-79. https://doi.org/10.1146/annurev. publhealth.26.021304.144652

11. Labiak VB, Leite ML, Virgens Filho JS, Stocco C. Fatores de exposição, experiência no trânsito e envolvimentos anteriores em acidentes de trânsito entre estudantes universitários de cursos na área da saúde, Ponta Grossa, PR, Brasil. Saúde Soc. 2008;17(1):33-43. https://doi. org/10.1590/s0104-12902008000100004

12. Saunders JB, Aasland OG, Amundsen A, Grant M. Alcohol consumption and related problems among primary health care patients: WHO collaborative project on early detection of persons with harmful alcohol consumption - I. Addiction. 1993;88(3): 349-62. https://doi.org/10.1111/j.1360-0443.1993.tb00822.x

13. Méndez, EB. Uma versão brasileira do AUDIT - Alcohol Use Disorders Identification Test [dissertação]. Pelotas: Universidade Federal de Pelotas; 1999.

14. Eaton DK, Kann L, Kinchen S, Shanklin S, Ross J, Hawkins J, Harris WA, Lowry R, McManus T, Chyen D, Lim C, Whittle L, Brener NDI. Youth Risk Behavior Survey - United States, 2009. MMWR Surveill Summ. 2010;59(5):1-142.

15. Toroyan T, Peden M. Youth and Road Safety. Geneva: WHO; 2007.

16. Brasil. Presidência da República. Secretaria Nacional de Políticas sobre Drogas. I Levantamento nacional sobre o uso de álcool, tabaco e outras drogas entre universitários das 27 capitais brasileiras. Brasília: SENAD; 2010. 
17. Marin-León L, Vizzotto MM. Comportamentos no trânsito: um estudo epidemiológico com estudantes universitários. Cad Saúde Pública. 2003;19(2):515-23. https://doi.org/10.1590/S0102$311 \times 2003000200018$

18. Caixeta RC, Minamisava R, Oliveira LMAC, Brasil VV. Morbidade por acidentes de transporte entre jovens de Goiânia, Goiás. Ciênc Saúde Coletiva. 2010;15(4):2075-84. https://doi.org/10.1590/ S1413-81232010000400021

19. Silva LVER, Malbergier A, Stempliuk VA, Andradel AG. Fatores associados ao consumo de álcool e drogas entre estudantes universitários. Rev Saúde Públ. 2006;40(2):280-8. https://doi. org/10.1590/S0034-89102006000200014

20. Chiapetti, N, Serbena CA. Uso de álcool, tabaco e drogas por estudantes da área de saúde de uma Universidade de Curitiba. Psicol Reflex Crít. 2007;20(2):303-13. https://doi.org/10.1590/ S0102-79722007000200017

21. Baumgarten LZ, Gomes VLO, Fonseca AD. Consumo alcoólico entre universitários(as) da área da saúde da Universidade Federal do Rio Grande/RS: subsídios para enfermagem. Esc Anna Nery. 2012;16(3):530-5. https://doi.org/10.1590/S141481452012000300015
22. Peuker AC, Fogaça J, Bizarro L. Expectativas e beber problemático entre universitários. Psic Teor e Pesq. 2006;22(2):193-200. https:// doi.org/10.1590/S0102-37722006000200009

23. Pillon SC, Corradi-Webster CM. Teste de identificação de problemas relacionados ao uso de álcool entre estudantes universitários. Rev Enferm UERJ. 2006;14(3):25-32.

24. National Highway Traffic Safety Administration. 2007National Roadside Survey of Alcohol and Drug Use by Drivers: Alcohol Results. Washington DC: NHTSA; 2009.

25. Gawryszewski VP, Koizumi MS, Mello-Jorge MHP. As causas externas no Brasil no ano 2000: comparando a mortalidade e a morbidade. Cad Saúde Pública. 2004;20(4):995-1003. https://doi.org/10.1590/ S0102-311X2004000400014

26. O'Connor SS, Whitehill JM, King KM, Kernic MA, Boyle LN, Bresnahan BW, Mack CD, Ebel BE. Compulsive cell phone use and history of motor vehicle crash. J Adolesc Health. 2013;53(4):512-9. https://doi.org/10.1016/j.jadohealth.2013.05.015

27. Charalambous MP. Alcohol and accident and emergency department: a current review. Alcohol Alcohol. 2002;37(4): 307-12. https://doi.org/10.1093/alcalc/37.4.307 